\title{
Unit per Animal
}

National Cancer Institute

\section{Source}

National Cancer Institute. Unit per Animal. NCI Thesaurus. Code C73773.

An arbitrary dosing unit expressed in unit(s) per animal. 